DOI: $10.14451 / 2.126 .50$

\title{
ГЕНЕЗИС И ЭВОЛЮЦИЯ НАУЧНЫХ ПОДХОДОВ К ИССЛЕДОВАНИЮ КАТЕГОРИИ «ИНСТИТУЦИОНАЛЬНЫЙ ИНТЕРЕС»
}

\author{
(c) 2018 Мишин Алексей Юрьевич \\ Руководитель подкомитета по защите прав кредиторов комитета по финансовым услугам \\ Общероссийская общественная организация «Деловая Россия» \\ 119121, Москва, 2-й Вражский переулок, д. 1 \\ E-mail: Alink2501@gmail.com
}

В статье рассматриваются методологические и теоретические подходы к исследованию категории «институциональный интерес», выявляется неразрывная связь и противоречивый характер взаимодействия экономических и институциональных интересов субъектов хозяйственной системы.

Ключевые слова: интерес, институциинальный интерес, институциональные отношения, экономический интерес, экономические школы

Категория «институциональный интерес» даже по своему звучанию отчетливо подчеркивает свою связь с институциональной теорией, зародившейся в конце XIX - начале XX веков в США. Поставив вопрос о стихийном естественном отборе институтов в процессе денежного соперничества индивидов, данное направление в рамках анализа коллективных действий хозяйствующих субъектов, мотивированных желанием удовлетворить их институциональные потребности, подошло к идее необходимости направленного преобразования институтов как одного из ключевых факторов развития экономической системы.

Институциональный интерес - это одна из базовых категорий институциональной ветви экономической мысли, неотъемлемый атрибут сравнительно молодой и быстро развивающейся области экономической науки. Именно в рамках данного направления изучаемая формулировка получила свое закрепление, если можно так выразиться, «научный статус», превратилась в устоявшееся словосочетание, часто используемое в научных изысканиях, посвященных изучению институционального пространства современной экономики. Не оспаривая данного факта, все же придется поставить под сомнение, что фундамент этой столь часто употребляемой в экономической литературе дефиниции был заложен на не столь отдаленном рубеже XIX$\mathrm{XX}$ веков.

Любые экономические исследования, в том числе и труды ученых глубокой древности, не имеющие статус научных, были посвящены изучению экономических отношений между отдельными индивидами, например, в форме конкретной сделки купли-продажи или аренды, либо затрагивался более масштабный срез отношений между социальными слоями, в частности, при решении вопросов налогообложения, денежного обращения и прочих. Социальные отношения, разновидностью которых являются и экономические, предполагают целенаправленный и чаще всего двусторонний характер интеракций. Индивиды, осуществляющие взаимодействие, делают это вовсе не на пустом месте, они движимы внутренними мотивами, в том числе и мотивом получения выгоды. В древней египетской, вавилонской, китайской, индийской, греческой или римской литературе, конечно, формирование экономических отношений в обществе не анализируется на столь глубоком уровне, но тем не менее, пусть и косвенно, промеж строк, авторы описывают интересы участников хозяйственной жизни, объясняют, какие цели преследуют они, вступая во взаимодействие друг с другом, и к каким результатам, это может привести. Более того, поскольку литература пишется в основном для привилегированных слоев населения, в ней часто подчеркивается такой момент, что экономические отношения внутри государства могут носить стабильный, устойчивый характер, если будут хорошо структурированы. Ключевая задача правителя, его базовый интерес, реализующийся в форме экспансии власти, обязательно предполагает создание правового поля, написание законов, издание указов, которые регламентировали бы сложив- 
шиеся экономические отношения, загнали бы деятельность хозяйствующих субъектов в определенные рамки в целях повышения ее эффективности. Пусть и в примитивной форме, без должной системы аргументации, доказательной базы, что лишний раз подчеркивает ее ненаучный характер, но литература древнего мира, как, впрочем, и средневековья, описывает экономические и институциональные интересы хозяйствующих субъектов.

Следующий виток качественно новых, и уже научных рассуждений в этой области датируется периодом зарождения экономических школ. Эпоха Просвещения, ознаменованная первой научной революцией и появлением классической науки, не только существенно расширила область изучения, но и отразилась на качестве исследований. Сложился совершенно иной тип рациональности, для которого свойственно философское понимание тождества мышления и бытия. Ученые того периода в попытке отыскать одну единственную идеальную конструкцию, которая бы полностью соответствовала изучаемому объекту, стараются объяснить все явления и процессы путем установления между ними причинно-следственных связей. Каузальный метод, столь широко применяемый при построении новой механистической картины миры, затронул и социально-гуманитарные исследования, в том числе и изучение вопроса экономических и институциональных интересов.

В фундаментальном труде шотландского экономиста А. Смита «Исследование о природе и причинах богатства народов» [5], который, несмотря на свое издание в 1776 году, до сих пор является настольной книгой современных исследователей в области экономической науки, экономические и институциональные интересы изучаются достаточно подробно. Хотя не все авторы, занимающиеся анализом смитовских теорий, замечают то, что основатель классической политической экономии акцентирует внимание читателей в своих трудах на изучении институциональных интересов. Часто концепции «экономического эгоиста», «невидимой руки»и «ночного сторожа» рассматриваются весьма поверхностно, без учета взаимосвязи между ними.

А. Смит, частично заимствуя идеи своих современников Д. Юма, А. Фергюссона, Й. Бентама о человеческой природе, о соотношении рационального и чувственного в процессе принятия индивидом решений, приходит к выводу об универсализме законов человеческого поведения. Людьми движут их потребности, пытаясь удовлетворить свои стремления к жизненным удобствам, личным удовольствиям, комфорту, они вынуждены участвовать в жизни социума, в общественном разделении труда.

Выстраивая достаточно жестко детерминированную научную модель социально-экономических отношений, А. Смит утверждает, что личный интерес выступает лучшим стимулом экономического развития. Результатом реализации частной заинтересованности индивида в собственной выгоде является удовлетворение общественных интересов в форме роста благосостояния участников рыночных отношений. Поэтому, по мнению А. Смита, экономический эгоист, движимый корыстными интересами, на самом деле не порочен, а полон добродетелей, как низших - стремление к личным удовольствиям, так и высших, вытекающих из чувства симпатии. Под симпатией А. Смит подразумевает мысленную способность поставить себя на место другого человека, именно это естественное чувство подсказывает разуму общие нравственные правила, что можно трактовать как наличие у индивида не только экономического, но и институционального интереса, определяющего его поведение.

А. Смитом не отрицается необходимость существования общественных институтов. Именно их наличие, как и действие экономических законов в форме общественного разделения труда или свободной конкуренции, ограничивает часто разрушительное действие эгоистичных порывов хозяйствующих субъектов. Только тогда, когда частные интересы зажаты в институциональную матрицу хозяйственных отношений, они выступают благом для последних, являясь стимулом экономического развития общества, а не его разрушения.

Смитовское утверждение о том, что приложение индивидуальных усилий и капиталов направляется «невидимой рукой» к благотворному для общества «спонтанному» порядку самопроизвольно возникающих институтов, ставится многими исследователями под сомнение. Превосходство «спонтанных порядков» не является бесспорным.

Вывод о безусловном предпочтении игры частных интересов над какими-либо формами коллективного экономического регулирования независимо от исторических и географических 
условий жестко критикуется представителями немецкой исторической школы. Ее предвестник Ф. Лист в своем учении о национальных производительных силах не раз акцентировал внимание на особой роли институтов в экономической системе, подчеркивая, что процесс их создания носит вовсе не спонтанный, самопроизвольный характер, это целенаправленная деятельность социума [4].

Критикуя экономический индивидуализм классической школы, немецкие исследователи выдвинули формулу тройственной структуры хозяйственных интересов:

- частная заинтересованность;

- общественный (государственный) интеpec;

- каритативные стремления (от лат. «caritas» - благожелательность, сострадание, благотворительность).

По их мнению, именно множественность мотивов (интересов) субъектов, сдобренная этнической составляющей, формирует хозяйственное поведение. Система хозяйственных отношений в исторической школе выстраивается на совершенно иных методологических принципах. Если у А. Смита общественные (институциональные) интересы определяются путем обращения к потребностям отдельных личностей, и являются своего рода инструментом продвижения к индивидуальным целям, то, например, с позиции М. Вебера, рассматривающего общество как «живую» организованную систему, у последней имеются свои собственные цели, общественные (институциональные) интересы, довлеющие над частными (экономическими), и нередко определяющие их. «Индивид в той или иной мере, в какой он входит в сложное переплетение рыночных отношений, вынужден подчиняться нормам капиталистического хозяйственного поведения. В течение долгого времени нарушающий эти нормы, экономически устраняется столь же неизбежно, как и рабочий, которого просто выбрасывают на улицу, если он не сумел или не захотел приспособиться к ним» [3].

Эта мысль М. Вебера получает новое рождение в работах институционалистов. Каких-то специализированных исследований, посвященных проблеме институционального интереса, в рамках данной ветви экономической науки, нет. Об институциональном интересе и его наличии у хозяйствующих субъектов мы можем услышать только в общих рассуждениях о том, что из себя представляют институты и какова их роль в экономической системе.

Не вдаваясь в детали, отметим, что под институтом чаще всего подразумевается правило или набор правил поведения в отношениях между людьми. Это правило ограничивает пространство допустимого поведения и тем самым упорядочивает взаимодействие. Возникать оно может спонтанно, либо насаждаться сознательно с помощью государственных мер или частных соглашений. На ряду с правилом, описывающим желаемую модель поведения, неотъемлемой частью института является механизм принуждения к исполнению данного правила, который может носить эндогенный характер в форме убеждений и привычек, а может быть экзогенным, поддерживаемым внешними авторитетами. Ключевой функционал института - придать взаимодействию людей систематичность, благодаря чему могут возникать более или менее надежные ожидания относительно способов поведения других субъектов и становятся возможными отношения доверия. Уровень доверия к правилам и связанным с ним стимулам оказывает существенное влияние на процесс и результаты хозяйственных отношений [1].

Столь высокая значимость институтов в хозяйственной деятельности субъектов очевидно свидетельствует о том, что последние на ряду с экономическими интересами имеют и институциональные интересы, побудительные мотивы к формированию институтов и поддержанию их эффективного функционирования. Наличие институциональных ограничений является условием реализации экономических интересов участников хозяйственных отношений, поскольку наложение на их действия определенных рамок, систем правил, позволяет регламентировать даже не столько их поведение в целом, сколько набор альтернатив, определяющих будущий выбор экономических агентов.

Мы не совсем согласны с тем утверждением, что хозяйственная система - это самостоятельный живой организм, имеющий свой собственный институциональный интерес. Правдоподобнее выглядит предположение, что существуют разрозненные институциональные интересы множества участников экономических отношений, которые могут иметь либо достаточно высокий уровень конвергенции, либо, напротив, находится в ситуации конфронтации. В этих условиях возникновение общих правил совмест- 
ной жизни и следование им осуществляется тем легче, чем больше сходимость имеющихся интересов. Эта точка зрения стала определяющей для работ, в которых проблема институтов моделируется и объясняется с помощью теории игр.

Институциональные интересы тесно связаны с экономическими, поскольку, как уже было сказано выше, являются условиями реализации последних. В этой связи общепринятой точкой зрения считается, что институциональные интересы лишены самостоятельной природы, играют второстепенную роль по отношению к экономическим, производны от них. Ни один хозяйствующий субъект не захочет поддерживать институциональный порядок, который не позволит ему извлекать доход от находящегося в его собственности фактора производства. Спорить с этим тезисом сложно, он полностью соответствует мейнстриму экономической науки. Неоклассика и кейнсианство рассматривают субъекта как атрибут функции либо полезности, либо прибыли, при таком раскладе институциональные отношения предстают в терминологии К. Маркса в качестве надстройки к экономическим. Но если вырваться за рамки теоретических конструкций неоклассической и кейнсианской ветвей экономической мысли, то с уверенностью утверждать, что экономические интересы первостепенны по отношению к институциональным, невозможно. На ряду с корыстными мотивами, нацеленными на удовлетворение личных потребностей, у индивидов могут быть и потребности альтруистического толка. Так, по мнению Г. Беккера, альтруизм есть ни что иное как один из элементов модели максимизации полезности, ведь благополучие других представляется частью совокупной суммы благ, которой мы располагаем [2]. Таким образом, репутация, доверие и другие аспекты человеческого поведения, являющиеся альтруистическими и не сочетающиеся с индивидуальной максимизацией личной выгоды, в некоторых ситуациях оказываются свойствами, наиболее эффективно ведущими к выживанию.

Рассматривая генезис институциональных отношений, придется согласиться с тем, что институциональные интересы коренятся в экономических отношениях общества. Однако по мере развития человечества ситуация становится не столь однозначной, присудить пальму первенства экономическим или институциональным мотивам, определяющим социальное поведение, сложно, и те, и другие могут играть активную роль в принятии решений и совершении действий акторами, что необходимо учитывать в реальной экономической действительности.

\section{Библиографический список}

1. Анализ экономических систем: основные понятия теории хозяйственного порядка и политической экономии/ под общ. Ред. А. Шюллера, Х. Г. Крюссельберга; пер. с нем. Москва. 2006.

2. Беккер Г. Экономический анализ и человеческое поведение// THESIS. 1993. № 1.

3. Вебер М. Основные социологические понятия // Избр. произведения: пер. с нем. Москва. 1990.

4. Лист Ф. Национальная система политической экономии/ Под ред. К.В. Трубникова; пер. с нем. Санкт-Петербург. 1981.

5. Смит А. Исследование о природе и причинах богатства народов/ Москва. 1962. 